\title{
The relationship between ambient temperature and acute respiratory and cardiovascular diseases in Shenyang, China
}

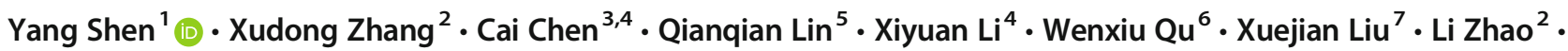 \\ Shijie Chang ${ }^{1}$
}

Received: 6 September 2020 / Accepted: 1 December 2020 / Published online: 6 January 2021

(C) The Author(s), under exclusive licence to Springer-Verlag GmbH, DE part of Springer Nature 2021

\begin{abstract}
The purpose of this study was to analyze the acute effect of ambient temperature on hospitalization due to acute exacerbation of chronic obstructive pulmonary disease (AECOPD), stroke, and myocardial infarction (MI) in Shenyang, China. We used the distributed delayed nonlinear model to evaluate the impact of ambient temperature on respiratory and cardiovascular diseases. The study population was divided into four groups: $<65$ group and $\geq 65$ age groups, female and male groups. The $<65$ age group of AECOPD patients was more likely to be affected by high ambient temperature, while the $\geq 65$ age group of AECOPD patients was more sensitive to low ambient temperature. The hospitalization risk of MI admission increased in the $\geq 65$ age group at 1-8 days delay under low ambient temperature conditions.
\end{abstract}

Keywords Ambient temperature $\cdot$ Acute hospitalization $\cdot$ Distributed delay nonlinear model $\cdot$ Acute exacerbation of chronic obstructive pulmonary disease

\section{Introduction}

Respiratory, cardiovascular, and cerebrovascular diseases are the leading causes of death worldwide (Ryan et al. 2019; Pranata et al. 2020). According to the Global Burden of Disease Study 2015, approximately 3.2 million people have died from chronic obstructive pulmonary disease (COPD). The prevalence of COPD has increased to $44.2 \%$ from $11.6 \%$ in 1990 (Dang et al. 2019; GBD 2015 Chronic Respiratory Disease Collaborators 2017). Another study indicated that by 2025, approximately 1.5 million individuals in Europe will suffer a stroke and the associated incidences of re-

Yang Shen and Xudong Zhang contributed equally to this work.

Responsible Editor: Lotfi Aleya

Li Zhao

1zhaoli@163.com

Shijie Chang

sjchang@cmu.edu.cn

1 Division of Biomedical Engineering, China Medical University, Shenyang 110122, Liaoning, China

2 Department of Pulmonary and Critical Care Medicine, Shengjing Hospital of China Medical University, No. 36 Sanhao Road, Heping District, Shenyang 110000, Liaoning, China hospitalization, recurrent events, dementia mild cognitive disorder, and depression will increase (Béjot et al. 2016). Myocardial infarction (MI) is a cardiovascular disease that has physiological and psychological effects. Feng et al.'s study showed that the prevalence of depression among patients with MI was $28.70 \%$ (Feng et al. 2019). Considering the high incidence of COPD, stroke, and MI, all of which lower a patient's quality of life, there is an urgent need to better understand disease risk factors.

Several studies have demonstrated that ambient temperature may be an important risk factor for COPD, stroke, and MI in China (Chen et al. 2019; Qi et al. 2020). One study 
Fig. 1 The number of stroke patients' hospitalization during the study period

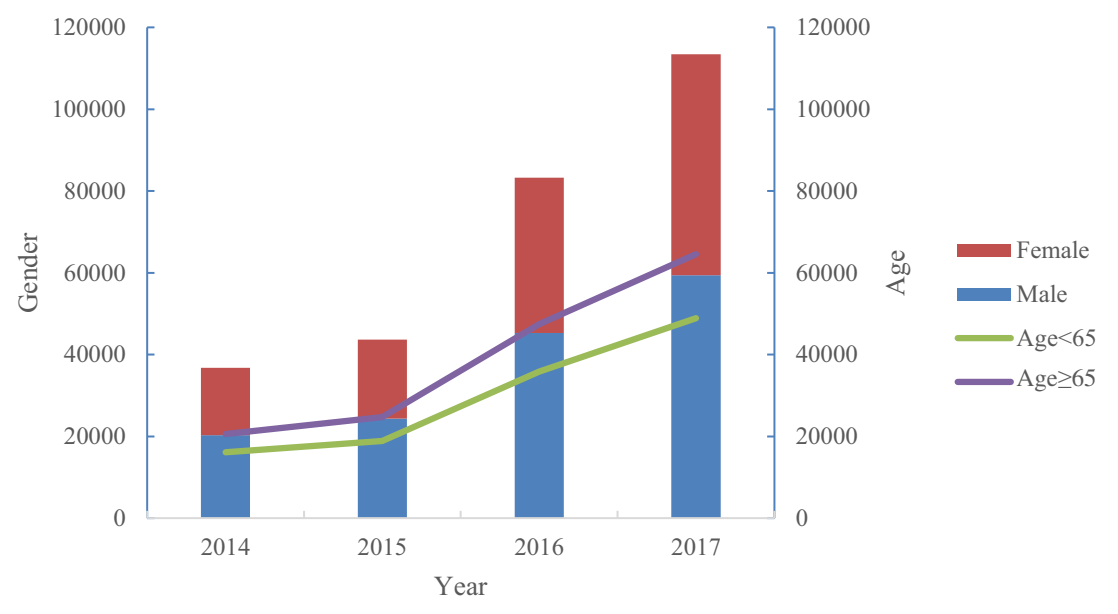

conducted in Changchun, China, that evaluated changes in ambient temperature on consecutive days found that the elderly and females were at a greater risk of acute disease exacerbation (Ma et al. 2020). Lian et al. found that an increase of 1 ${ }^{\circ} \mathrm{C}$ increased stroke risk by $1.13 \%(0.58-1.68 \%)$ and that a decrease of $1{ }^{\circ} \mathrm{C}$ increased the risk by $1.2 \%(0.84-1.57 \%)$ (Lian et al. 2015). One survey in the Vietnam North-Central Coast region showed that the risk of MI hospital admission increased by $11 \%$ (95\% confidence interval (CI): 0.91-1.35) at moderately low temperatures and increased by $25 \%(95 \%$ CI: 1.02-1.55) at extremely low temperatures (Thu Dang et al. 2019). These studies support a link between ambient temperature and acute exacerbation of respiratory and cardiovascular diseases. However, these studies were conducted in different geographical regions with varying climates. The goal of this study was to investigate the association between ambient temperature and acute exacerbation of COPD (AECOPD), stroke, and MI in Shenyang, China.

\section{Methods}

The admission records of patients with AECOPD, stroke, and MI were obtained from Shenyang Medical Healthcare
Security Administration. The records included admission date, gender, age, date of discharge, and admission number. Mean temperature $\left({ }^{\circ} \mathrm{C}\right)$ and relative humidity $(\%)$ were attained from the Shenyang Meteorological Bureau. We used the distributed delayed non-linear model (DLNM) to determine the association between ambient temperature and disease. The DLNM can be used as an index of the relationship between cumulative hysteresis effect, exposure, and response as shown in equation (1) (Gasparrini et al. 2010; Forbes 2010):

$\log [E(y t)]=\alpha+\phi_{1}$ Temperature $+n s($ humidity,$d f)+s($ time,$d f)+$
$s($ pressure,$d f)+\phi_{2}$ factor $($ dow $)+\phi_{3}$ factor $($ holidays $)$

where $\alpha$ is the intercept value; $\varphi_{1}, \varphi_{2}$, and $\varphi_{3}$ are regression correlations; $E[(\mathrm{yt})]$ is the expected number of daily admissions at day $t$; df is the degrees of freedom; Temperature is ambient temperature; humidity is the daily relative humidity; pressure is the daily average pressure; dow is a dummy variable for the day of the week; ns represents a smoothed function of time $(\mathrm{df}=4)$, pressure ( $\mathrm{df}=5$ ), and humidity $(\mathrm{df}=3$ ) (Chen et al. 2019; Song et al. 2019; Luo et al. 2018a).
Fig. 2 The hospitalization variation of patients with myocardial infarction during research period

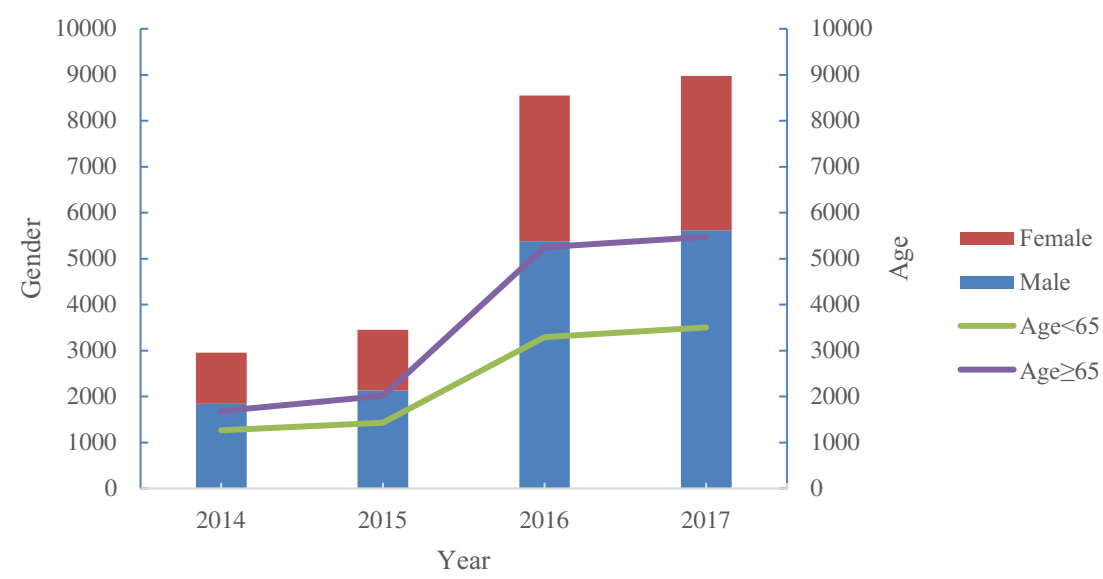


Fig. 3 The variation of admission rate for patients with AECOPD (AECOPD: acute exacerbation of chronic obstructive pulmonary disease)

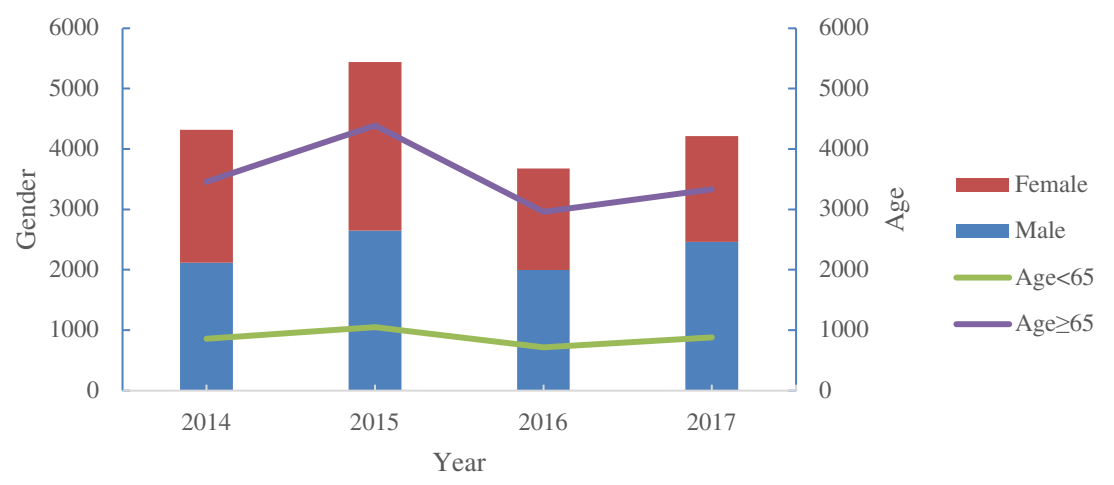

Analysis results are expressed as percent change of the relative risk (RR) of hospitalization and the 95\% CI for temperature change. Stratification analysis was used to compare the $<65$ age and the $\geq 65$ age groups, and the male and female groups. Statistical analysis was conducted using RStudio 4.0.2.

\section{Results}

\section{Descriptive results}

There were 276,736 stroke cases $(149,500$ male and 127,236 female); $56.8 \%$ was $\geq 65$ years old, and $43.2 \%$ was $<65$ years old. Figure 1 illustrates the trend of stroke morbidity during the study period. The incidence rate of stroke increased over time.

There were 26,235 MI cases $(16,408$ males and 9,827 females); $55.0 \%$ was $\geq 65$ years old, and $45.0 \%$ was $<65$ years old. Figure 2 shows the hospitalization variation of patients with MI. The incidence rate was greater in patients $\geq 65$ years old compared to those $<65$ years old. Morbidity was higher in males compared to females.

There were 17, 644 cases of AECOPD (9228 males and 8416 females); $80.2 \%$ was $\geq 65$ years old, and $19.8 \%$ was $<65$ years old. Figure 3 shows the variation of admission rate for patients with AECOPD. The incidence of AECOPD was more common in patients $\geq 65$ years old.

The meteorological factors involved in this study are presented in Table 1. The average ambient temperature, relative humidity, and air pressure were $9{ }^{\circ} \mathrm{C}, 46 \%$, and $1017 \mathrm{hPa}$, respectively.

\section{DLNM result for stroke}

The maximum RR and 95\% CI between ambient temperature and acute admission of stroke under different delay conditions are shown in Table 2. The maximum RRs and 95\% CIs in Lag $0-27$ were as follows: $<65$ age group [1.470 (95\% CI: $1.040-$ $2.078)]$ and $\geq 65$ age group [1.487 (95\% CI: 1.060-2.085)]; male group [1.567 (95\% CI: 1.120-2.193)] and female group [1.395 (95\% CI: 0.942-2.063)].

As shown in Fig. 4, there was a nonlinear relationship between ambient temperature and the whole population of acute stroke admission. The risk of admission reached a peak value when the ambient temperature was $-20^{\circ} \mathrm{C}$, and the risk persisted for 25 days when the temperature exceeded $20^{\circ} \mathrm{C}$.

The three-dimensional graph and contour map for the risk of male and female stroke admission under different delay days are shown in Fig. 5. The relationship between temperature and admission risk was fairly complex. When the temperature was between $3{ }^{\circ} \mathrm{C}$ and $20^{\circ} \mathrm{C}$, there was no impact in the female group. Lower temperatures exacerbated the risk of stroke admission for both the male and female groups, and the risk of stroke admission increased when the temperature was lower than $-11^{\circ} \mathrm{C}$ with a delay of $24-27$ days. The ambient temperature appeared to have a protective effect in the male population, and the risk of admission was reduced when the temperature ranged between $20^{\circ} \mathrm{C}$ and $30^{\circ} \mathrm{C}$ with a delay of 0-20 days.

Table 1 Descriptive statistics result for daily meteorological factors

\begin{tabular}{lllllll}
\hline Meteorological factors & $X \pm S$ & Min & $P_{25}$ & $P_{50}$ & $P_{75}$ & Max \\
\hline Temperature $\left({ }^{\circ} \mathrm{C}\right)$ & $9 \pm 13$ & -25 & -3 & 11 & 21 & 30 \\
Relative humidity $(\%)$ & $46 \pm 26$ & 2 & 17 & 51 & 67 & 98 \\
Pressure $(\mathrm{hPa})$ & $1017 \pm 71$ & 987 & 1008 & 1016 & 1025 & 1041 \\
Wind speed $(\mathrm{Km} / \mathrm{h})$ & $8 \pm 3$ & 2 & 6 & 8 & 10 & 17 \\
\hline
\end{tabular}

Min minimum, Max maximum, IQR interquartile range, $X$ mean value, $S$ standard deviation, $P_{25}$ the first quartile, $P_{50}$ the second quartile, $P_{75}$ the third quartile 
Table 2 Maximum relative risk (RR) and 95\% confidence interval (CIs) under different delay conditions for temperature and acute stroke admission

\begin{tabular}{lllll}
\hline & $\operatorname{Lag}_{0-6}$ & $\operatorname{Lag}_{0-13}$ & $\operatorname{Lag}_{0-20}$ & $\operatorname{Lag}_{0-27}$ \\
\hline Total & & & & \\
RR & 1.186 & 1.359 & 1.255 & 1.470 \\
$95 \% \mathrm{CI}$ & $1.044-1.347$ & $1.135-1.627$ & $0.997-1.579$ & $1.040-2.078$ \\
Age $<65$ & & & & \\
RR & 1.118 & 1.301 & 1.201 & 1.458 \\
$95 \% \mathrm{CI}$ & $0.975-1.281$ & $1.061-1.595$ & $0.922-1.565$ & $0.981-2.169$ \\
Age $\geq 65$ & & & & \\
RR & 1.210 & 1.412 & 1.304 & 1.487 \\
$95 \% \mathrm{CI}$ & $1.048-1.398$ & $1.179-1.690$ & $1.040-1.636$ & $1.060-2.085$ \\
Female & & & & \\
RR & 1.304 & 1.424 & 1.312 & 1.567 \\
$95 \% \mathrm{CI}$ & $1.141-1.491$ & $1.190-1.705$ & $1.047-1.645$ & $1.120-2.193$ \\
Male & & & & \\
RR & 1.093 & 1.319 & 1.206 & 1.395 \\
$95 \% \mathrm{CI}$ & $0.953-1.255$ & $1.080-1.612$ & $0.945-1.537$ & $0.942-2.063$ \\
\hline
\end{tabular}

The relationship between temperature and the risk of acute stroke hospitalization under different delay days is shown in Fig. 6. Low ambient temperatures increased the possibility of stroke admission in the $\geq 65$ age group and the $<65$ age group, and the $\geq 65$ age group was more susceptible to lower temperatures.

(a)

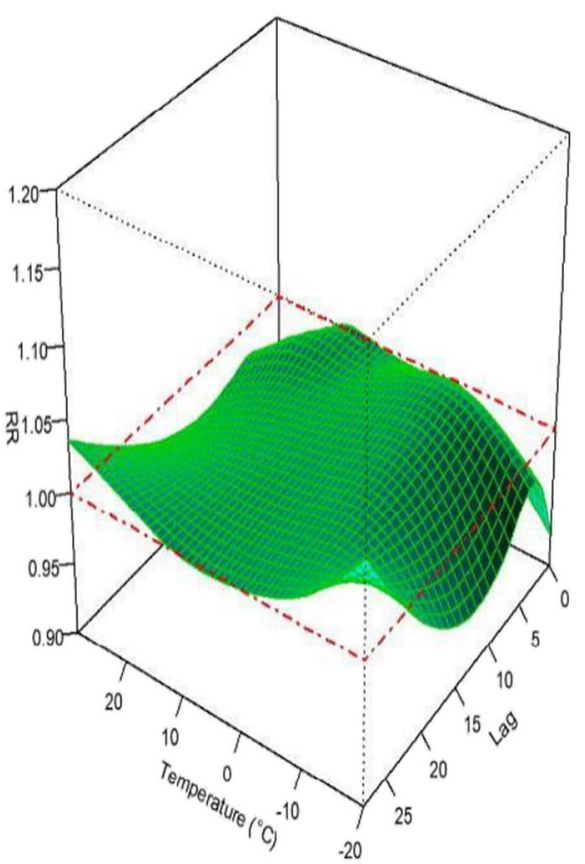

S 1(a) shows the curve variation between temperature and risk of stroke admission in females under different cumulative lag days. Under the conditions of cumulative $\operatorname{Lag}_{0-13}$ and $\operatorname{Lag}_{0-20}$ days, higher temperatures had a protective effect on the female group and the risk of admission was reduced. The risk of acute stroke admission among the female group decreased at first but then increased at cumulative $\operatorname{Lag}_{0-27}$ days. The association between temperature and the risk of acute stroke among the male group under different cumulative lag days is shown in S 1 (b). The shaded part represents the $95 \%$ CI. The upper left and right images show a cumulative lag of 6 days and a cumulative lag of 13 days, respectively. The risk of admission of stroke in the male group increased initially, but then decreased with increases in temperature; the bottom right shows the cumulative lag of 27 days. With the increase in temperature, the risk of admission in the male group decreased at first and then increased. The results based on age stratification are shown in S 1(c-d).

\section{DLNM result for MI}

The maximum RRs and their 95\% CIs for ambient temperature and acute $\mathrm{MI}$ admission under different delay conditions are summarized in Table 3. The maximum RRs and 95\% CIs were as follows: entire population [1.600 (95\% CI: 0.775 $3.302)],<65$ age group [2.132 (95\% CI: 0.704-6.460)], and $\geq 65$ age group [1.486 (95\% CI: 1.042-2.119)]. As shown in Fig. 7, there was no linear association between ambient

(b)

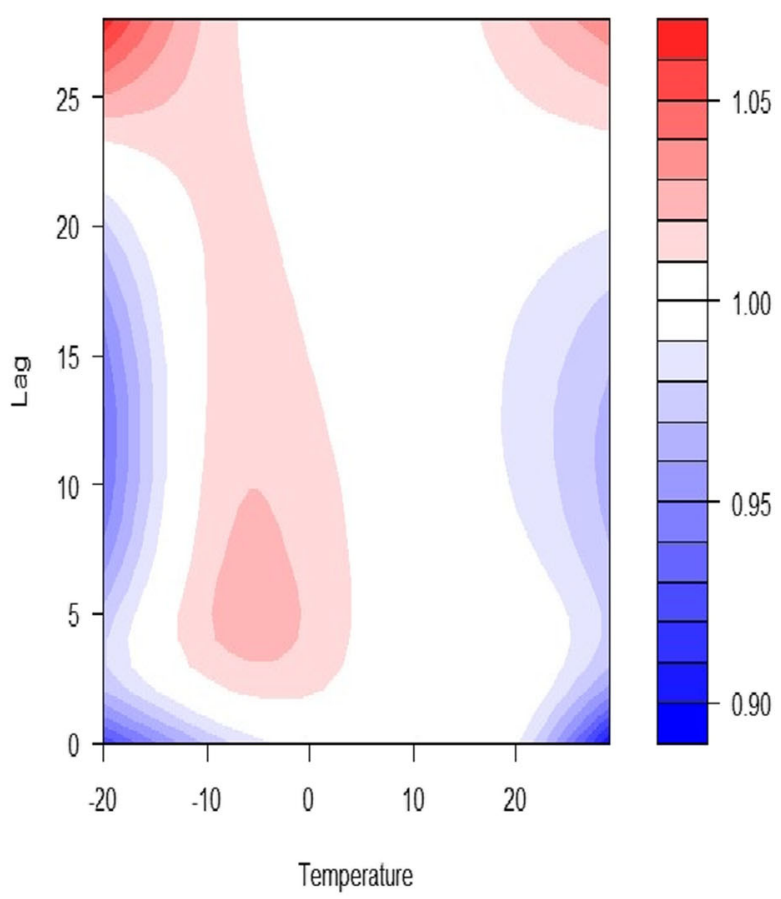

RR

.05

\author{
.
}

\section{(n)}

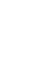




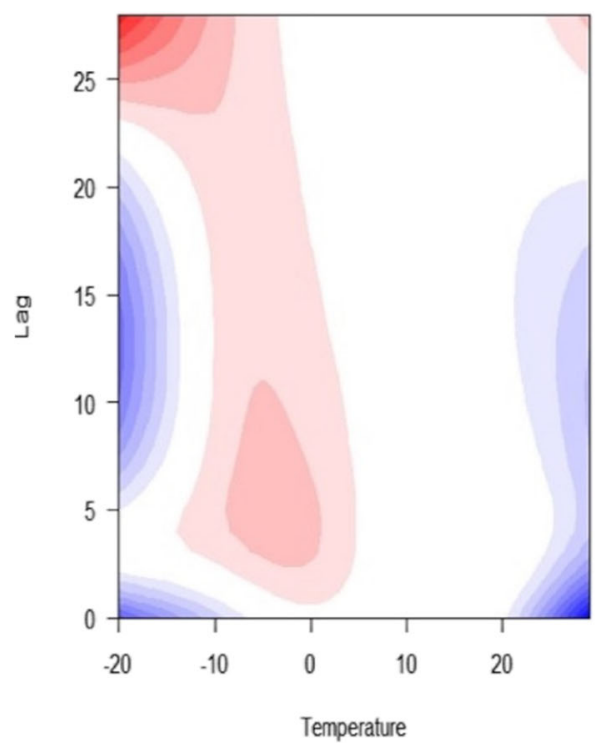

(a)

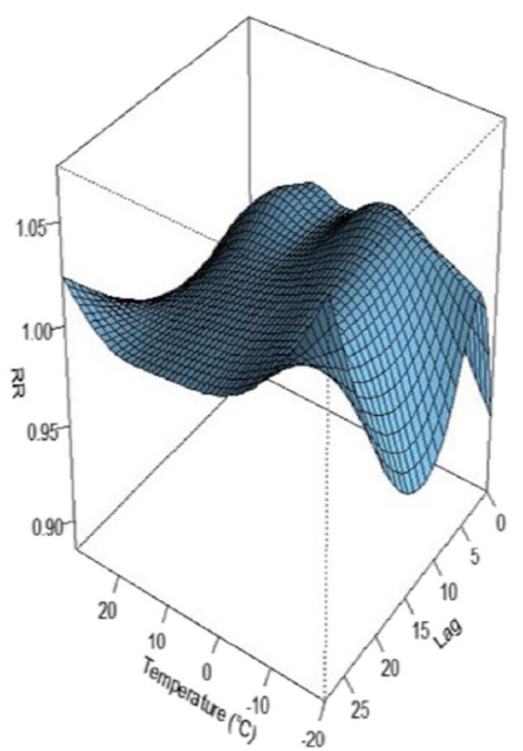

(c)
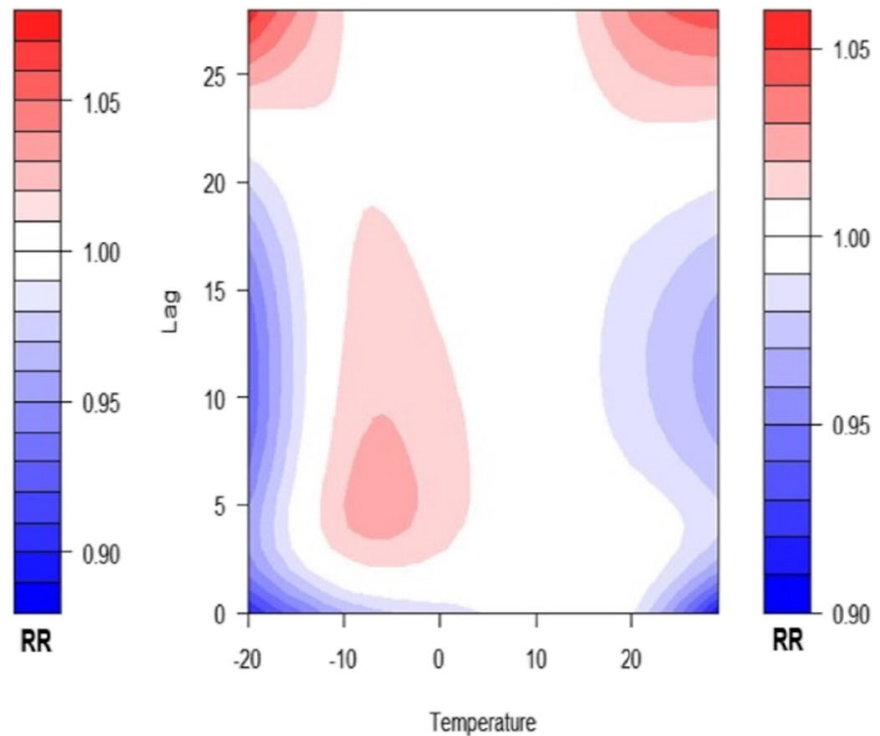

(b)

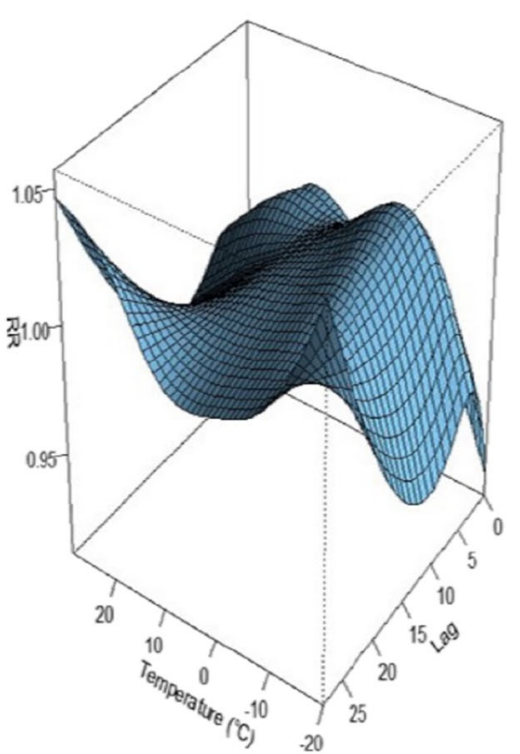

(d)

Fig. 5 The influence of ambient temperature on the risk of acute stroke admission based on the gender stratifications (a and $\mathbf{c}$, female; $\mathbf{b}$ and $\mathbf{d}$, male)

temperature and the entire population of acute MI admission. The data show that lower temperatures are a high-risk factor for MI admission when the delay is $2-8$ days. When the temperature was greater than $10^{\circ} \mathrm{C}$, the temperature did not affect the risk of $\mathrm{MI}$, and may actually have been protective.

The RR between temperature and MI hospitalization in the male and female groups under different delay days are shown in Fig. 8. When the delay was 0-6 days, low temperatures increased the RR of MI hospitalization. The effect of ambient temperature on $\mathrm{MI}$ in the $<65$ age group and $\geq$ age 65 group is provided in Fig. 9 The risk of MI hospitalization increased in the $\geq 65$ age group at $1-8$ days delay under low-temperature conditions. The effect of temperature on MI hospitalization based on gender stratification under different cumulative lag days is shown in S 2(a-b). The analysis based on age stratification and cumulative effect of temperature on MI hospitalization is shown in S 2(c-d).

\section{DLNM result for AECOPD}

The maximum RRs and 95\% CIs for temperature on AECOPD under different delay conditions are shown in Table 4. The maximum RRs and 95\% CIs under the condition of $\operatorname{lag}_{0-27}$ were as follows: entire population [2.061 (95\% CI: $0.772-5.500)],<65$ age group [1.972 (95\% CI: $0.910-$ $4.270)]$, and $\geq 65$ age group [1.972 (95\% CI: $0.910-4.270)]$. 


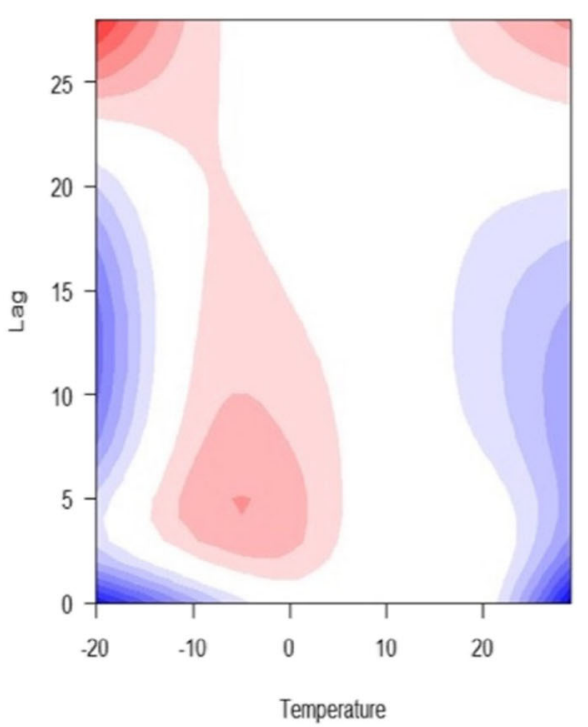

(a)

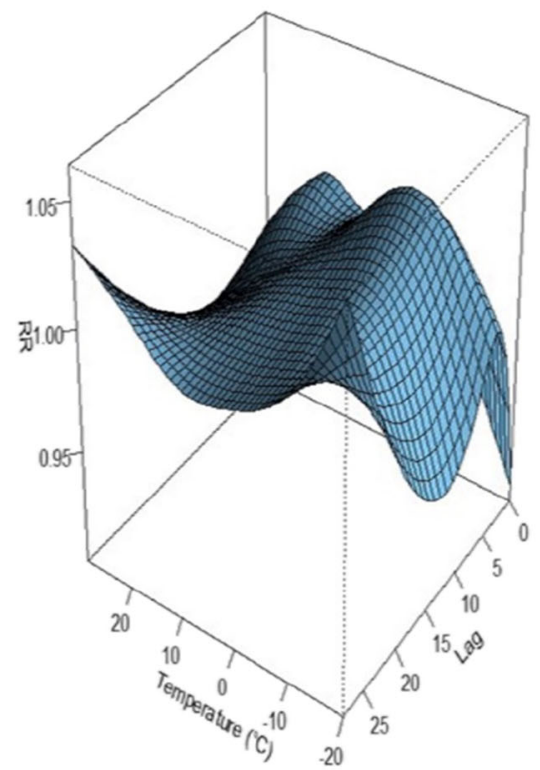

(c)
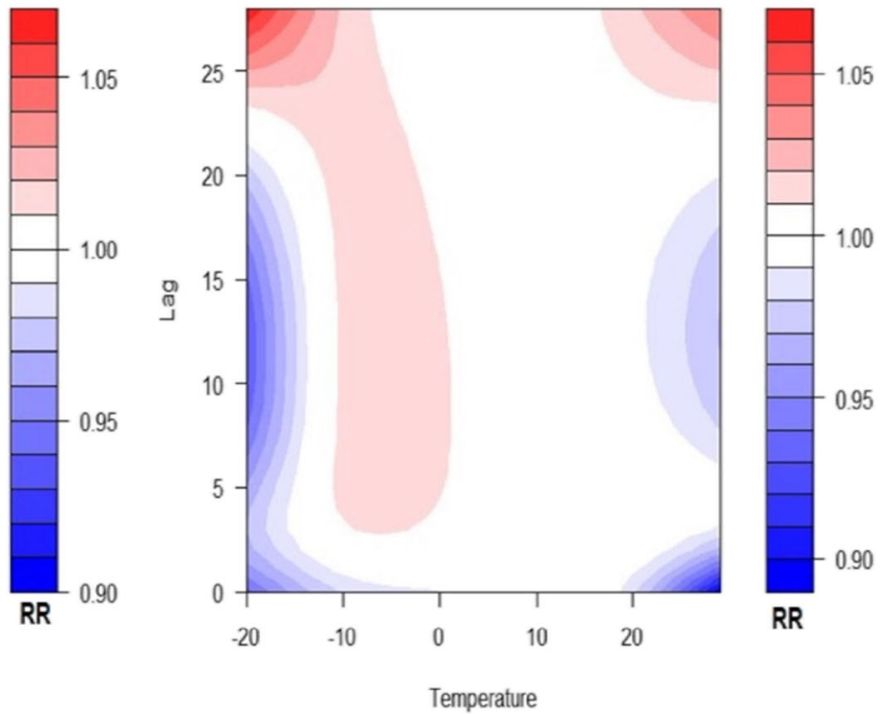

(b)

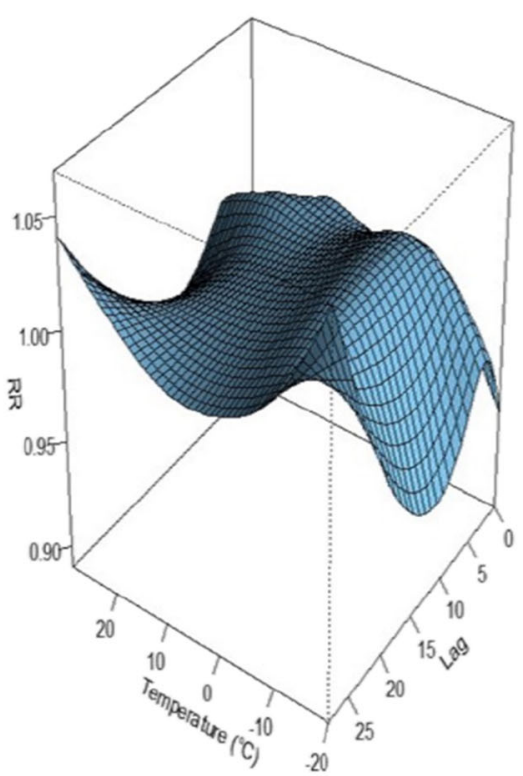

(d)

Fig. 6 The influence of ambient temperature on the risk of acute stroke admission based on the age stratifications $(\mathbf{a}$ and $\mathbf{c}$, age $\geq 65$ group; $\mathbf{b}$ and $\mathbf{d}$, age $<$ 65 group)

Figure 10 shows that the relationship between ambient temperatures on AECOPD hospitalization was non-linear. As temperature increased, the AECOPD hospitalization risk increased initially, decreased, and then increased again. Temperature had little effect on AECOPD hospitalization in the range of $5{ }^{\circ} \mathrm{C}$ to $10{ }^{\circ} \mathrm{C}$.

The risks of ambient temperature for AECOPD in the < 65 age group and $\geq 65$ age group are shown in Fig. 11 . The $<65$ age group was more likely to be affected by high temperature, while the $\geq 65$ age group was more sensitive to low temperature. The cumulative effect of temperature on the $<65$ and $\geq 65$ age group is presented in $\mathrm{S} \mathrm{3(a-b).} \mathrm{As} \mathrm{temperature} \mathrm{increased,} \mathrm{the} \mathrm{hospitalization}$ risk in the $\geq 65$ age group was stable after initially decreasing; when the temperature was greater than $-10{ }^{\circ} \mathrm{C}$, there was a protective effect. S 3(b) shows that high temperatures increased the risk of AECOPD hospitalization in the $<65$ age group.

Stratification based on gender is shown in Fig. 12. Temperature had a persistent delayed effect in both the male and female groups. The cumulative lag effect in the male and female groups is shown in S 3(c-d). When the temperature was lower than $-10{ }^{\circ} \mathrm{C}$, the RR of admission increased in the female group. High temperatures reduced the RR of AECOPD hospitalization in the male group. 
Table 3 Maximum relative risk (RR) and 95\% confidence interval (CIs) under different delay conditions for temperature and acute MI admission

\begin{tabular}{lllll}
\hline & Lag $_{0-06}$ & Lag $_{0-13}$ & $\operatorname{Lag}_{0-20}$ & Lag $_{0-27}$ \\
\hline Total & & & & \\
RR & 1.208 & 1.383 & 1.141 & 1.600 \\
$95 \% \mathrm{CI}$ & $1.004-1.455$ & $1.051-1.819$ & $0.786-1.657$ & $0.775-3.302$ \\
Age $<65$ & & & & \\
RR & 1.203 & 1.244 & 1.285 & 2.132 \\
$95 \% \mathrm{CI}$ & $0.739-1.958$ & $0.829-1.867$ & $0.556-2.972$ & $0.704-6.460$ \\
Age $\geq 65$ & & & & \\
RR & 1.245 & 1.486 & 1.103 & 1.297 \\
$95 \% \mathrm{CI}$ & $0.982-1.578$ & $1.042-2.119$ & $0.681-1.788$ & $0.513-3.279$ \\
Female & & & & \\
RR & 1.213 & 1.439 & 0.925 & 1.449 \\
$95 \% \mathrm{CI}$ & $0.910-1.618$ & $0.940-2.202$ & $0.5115-1.663$ & $0.472-4.449$ \\
Male & & & & \\
RR & 1.207 & 1.352 & 1.293 & 1.684 \\
$95 \% \mathrm{CI}$ & $0.961-1.516$ & $0.968-1.887$ & $0.821-2.035$ & $0.693-4.096$ \\
\hline
\end{tabular}

\section{Discussion}

The purpose of this study was to evaluate the effect of ambient temperature on AECOPD, stroke, and MI hospitalization rates in Shenyang, China, using the DLNM. Some studies have shown that the coronavirus outbreaks in 2003 and 2019 were closely related to environmental factors, such as temperature (Sehra et al. 2020; Sajadi et al. 2020; Auler et al. 2020). This led us to consider the link between environmental temperature and disease. This study was therefore designed to explore the relationship between respiratory and cardiovascular diseases, particularly COPD, one common underlying respiratory disease that is has been under investigated in the literature. Our study is of great significance for informing COPD patients, as well as stroke and MI patients, of the influence of temperature change on their risk of hospitalization.

It is reported that stroke morbidity in Shenyang is increasing, which is particularly alarming for both developing and developed countries. Previous research showed that stroke is connected to astogeny (Béjot et al. 2016), which is consistent with our findings in this study. Kes et al. also reported that acute hospital admissions are higher among males compared to females (Kes et al. 2016).

The findings of this study confirmed the previous research that ambient temperature adversely affects an individual's health. A study that included 4310 hemorrhagic or ischemic stroke patients in Japan demonstrated that when the mean temperature on the onset day was $1{ }^{\circ} \mathrm{C}$ lower than that of the previous week, the number of patient hospitalizations increased (Gomes et al. 2015). Alina Vodonos' study showed (a)

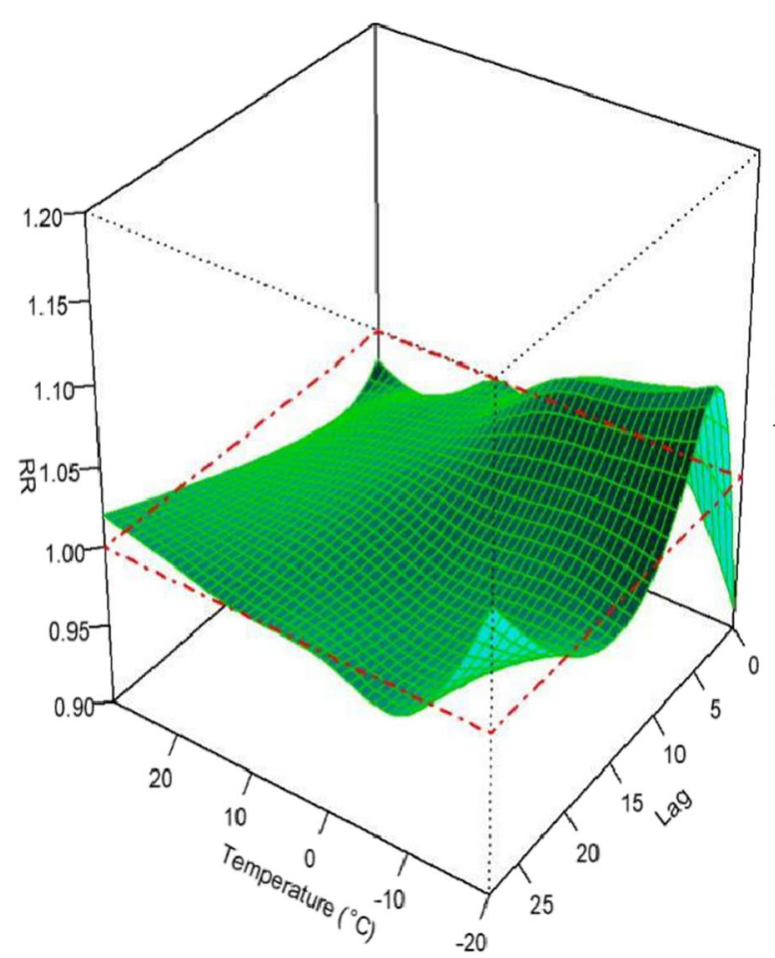

(b)

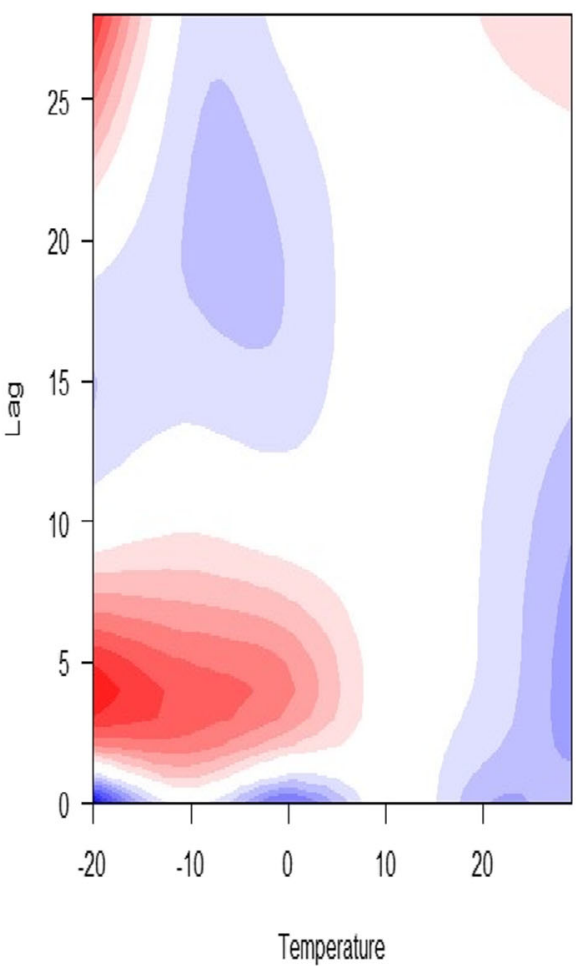

RR

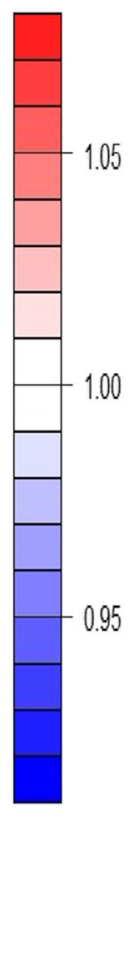

Fig. 7 Relationship between temperature and risk degree of acute admission of myocardial infarction patients in different delay days 


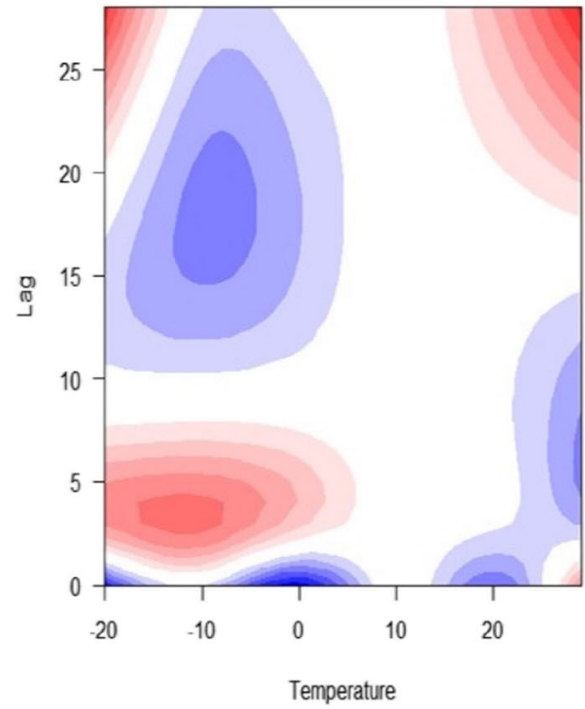

(a)

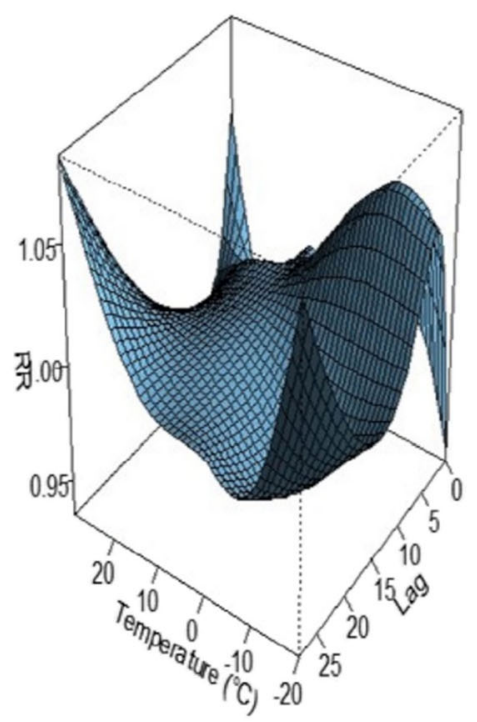

(c)
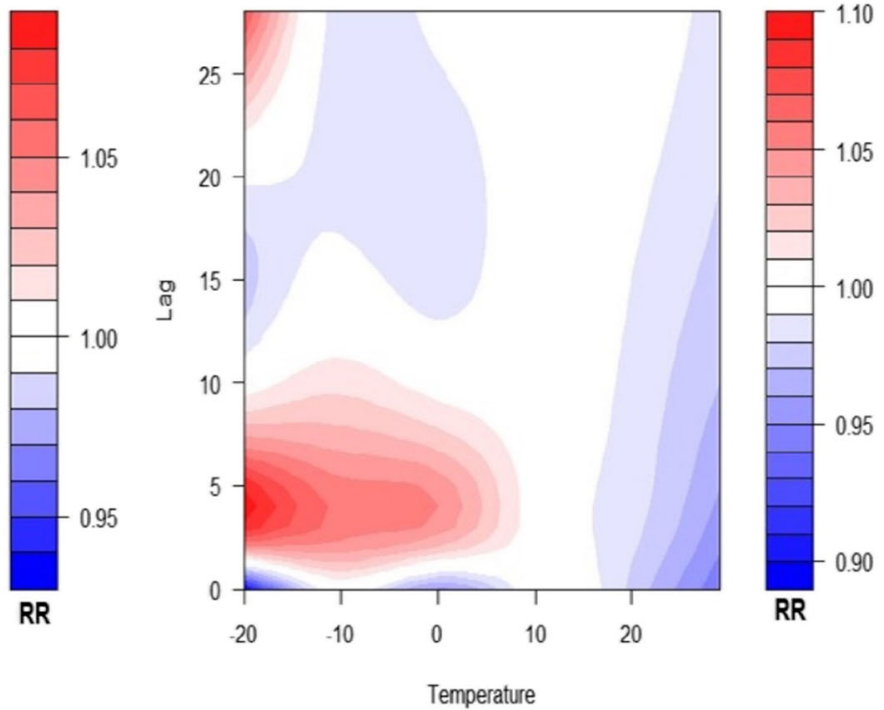

(b)

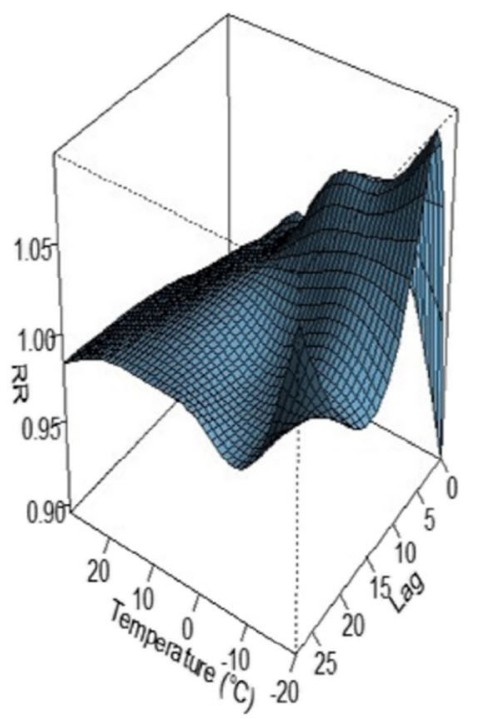

(d)

Fig. 8 The influence of ambient temperature on the risk of acute myocardial infarction admission based on the gender stratifications (a and $\mathbf{c}$, female; $\mathbf{b}$ and $\mathbf{d}$, male)

that ischemic stroke was associated with temperature; the odds ratio (OR) for an increase of $5{ }^{\circ} \mathrm{C}$ was $3.10(95 \%$ CI, 1.45 6.61) during the summer and 1.86 (95\% CI, 1.15-2.99) in the autumn (Vodonos et al. 2017). A case-crossover study in Maputo illustrated that a first stroke occurrence declined with minimum temperature changes between consecutive days of the preceding week (Gomes et al. 2015).

The present study found that lower temperatures increase the risk of stroke hospitalization. The pathogenesis of stroke induced by low ambient temperature may involve blood pressure fluctuations. Temperature drops enhance blood pressure by activating the sympathetic nervous system (SNS) and increasing the activity of the renin angiotensin system (RAS). In cold conditions, extracellular calcium ions enter the cells through L-type calcium channels, causing an increase in calcium concentration, initiating the excitation-contraction coupling mechanism of smooth muscle cells, inducing vasoconstriction (ZHU et al. 2002; Duncker et al. 1996). Previous studies have confirmed that hypertension is the most important cause of stroke. Vascular hypertension mainly manifests as abnormal arterial wall morphology, and the main pathological basis is hyaline degeneration of small arteries. Chronically uncontrolled hypertension can lead to atherosclerosis, which leads to narrowing or occlusion of the arteries, and ultimately stroke (Lawes et al. 2004; 


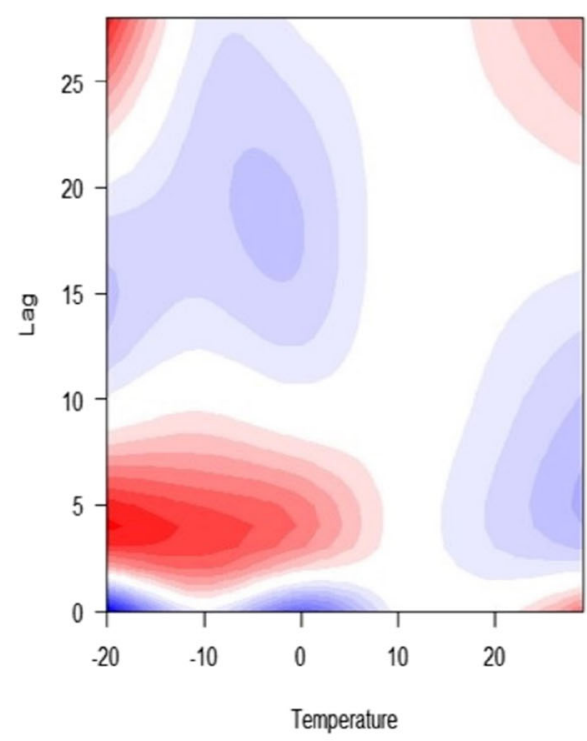

(a)

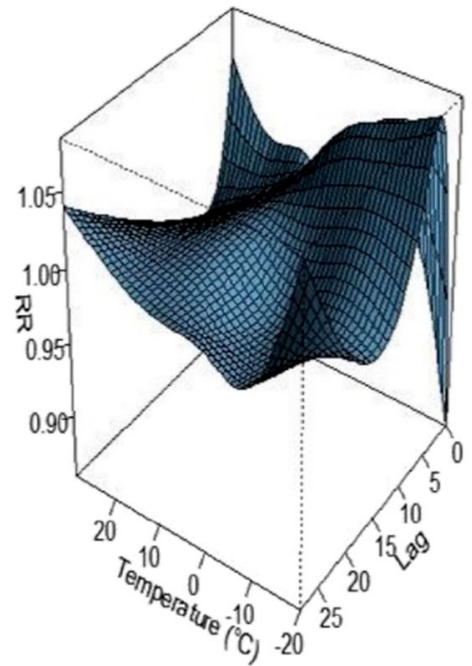

(c)
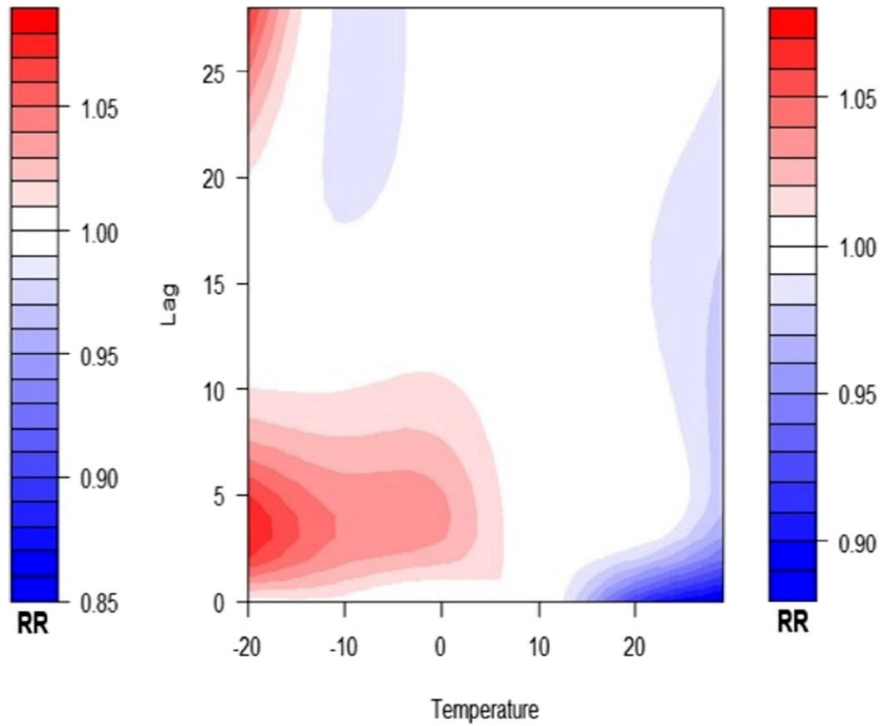

(b)

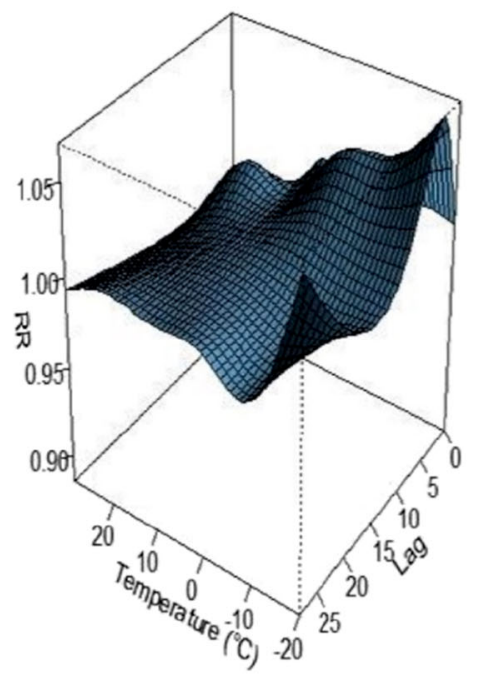

(d)

Fig. 9 The influence of ambient temperature on the risk of acute myocardial infarction admission based on the age stratifications (a and $\mathbf{c}$, age $\geq 65$ group; $\mathbf{b}$ and $\mathbf{d}$, age $<65$ group)

Gosmanova et al. 2016). Fluctuations in blood pressure can also cause stroke. Analysis of blood pressure monitoring in 1526 elderly males showed that blood pressure fluctuation was closely related to stroke, and the incidence of stroke increased by $2 \%$ for every $1 \mathrm{mmHg}$ increase in systolic blood pressure variation (Mena et al. 2017).

Our analysis showed that when the temperature ranged from $3{ }^{\circ} \mathrm{C}$ to $20{ }^{\circ} \mathrm{C}$, there was no impact on stroke hospitalization risk, and in fact, this temperature range conferred some protection. This supported Ganeshan's research, which showed that a comfortable temperature for humans ranges $20{ }^{\circ} \mathrm{C}-22{ }^{\circ} \mathrm{C}$ (Ganeshan and Chawla 2017). One meta-analysis involving 476,511 patients illustrated that older patients were more vulnerable to lower temperatures (Wang et al. 2016), which is consistent with our findings. Our finding that the impact of ambient temperature on stroke admissions was greater in the Males group contradicts a previous study by Luo et al. (Luo et al. 2018b). These discrepancies could be attributed to the fact that males in Shenyang may have an unhealthier lifestyle that involves alcohol consumption and smoking. Some surveys showed that alcohol is closely related to stroke occurrence (Larsson et al. 2016; Bardach et al. 2017). Another possible reason is that males are more likely to work outdoor jobs, which leads to more exposure to ambient air pollution. It has been 
Table 4 Maximum relative risk (RR) and 95\% confidence interval (CIs) under different delay conditions for temperature and acute COPD admission

\begin{tabular}{lllll}
\hline & $\operatorname{Lag}_{0-06}$ & $\operatorname{Lag}_{0-13}$ & $\operatorname{Lag}_{0-20}$ & $\operatorname{Lag}_{0-27}$ \\
\hline Total & & & & \\
RR & 1.336 & 1.253 & 1.311 & 2.061 \\
$95 \% \mathrm{CI}$ & $1.115-1.601$ & $0.935-1.680$ & $0.894-1.921$ & $0.772-5.500$ \\
Age $<65$ & & & & \\
RR & 1.865 & 1.707 & 1.756 & 1.972 \\
$95 \% \mathrm{CI}$ & $1.092-3.185$ & $0.757-3.847$ & $0.865-3.561$ & $0.910-4.270$ \\
Age $\geq 65$ & & & & \\
RR & 1.253 & 1.164 & 1.209 & 1.799 \\
$95 \% \mathrm{CI}$ & $1.048-1.498$ & $0.857-1.580$ & $0.794-1.839$ & $0.619-5.225$ \\
Female & & & & \\
RR & 1.292 & 1.315 & 1.237 & 2.903 \\
$95 \% \mathrm{CI}$ & $1.010-1.654$ & $0.909-1.900$ & $0.829-1.845$ & $0.844-9.990$ \\
Male & & & & \\
RR & 1.420 & 1.206 & 1.422 & 1.603 \\
$95 \% \mathrm{CI}$ & $1.119-1.802$ & $0.849-1.713$ & $0.835-2.422$ & $0.683-3.766$ \\
\hline
\end{tabular}

shown that exposure to air pollution can increase the risk of stroke hospitalization (Chen et al. 2020; Shah et al. 2015). We did not address air pollution in our analysis, which is one limitation of our study.

(a)

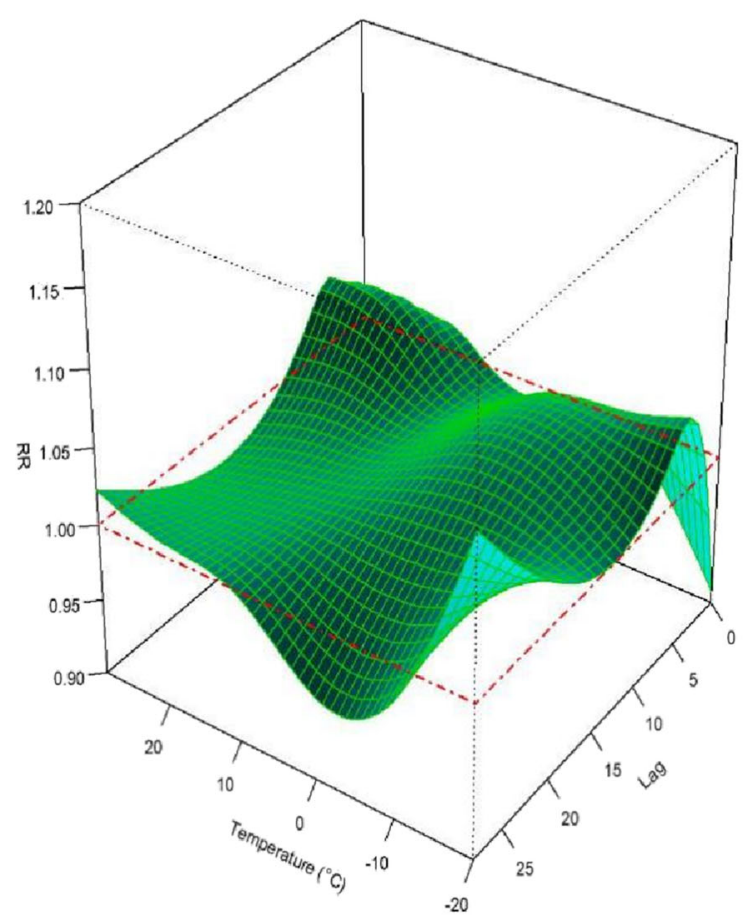

The findings of this study confirm the previous studies showing that ambient temperature is associated with MI mortality and morbidity. Sun et al. found that cold exposure, heat exposure, and exposure to heat waves were associated with an increased risk of MI (Sun et al. 2018). Similarly, according to Wasserman et al.'s research, there is an association between decreased root mean square successive difference (RMSSD) and increasing temperature in the summer and decreasing temperature in the winter. In a panel of cardiac rehabilitation patients, changes in ambient temperature were associated with decreases in biomarkers of heart rate variability and baroreflex sensitivity (Wasserman et al. 2014). Other reports suggested that variations in temperature trigger vasoconstriction, elevated blood pressure, and capillary contraction, which could explain the link between ambient temperature and MI morbidity (Mackay et al. 2019; Chang et al. 2004). The ability of changes in ambient temperatures to trigger MI could be explained as follows. First, increases in hemodynamic factors, such as blood viscosity, plasma cholesterol, vascular resistance, heart rate, and blood pressure, might lead to $\mathrm{MI}$ in colder weather (Giles et al. 2018; Lin et al. 2019). Moreover, temperature changes may impact immunity. Temperature changes can alter body fluids and cellular immunity, resulting in decreased immunity, decreased resistance, and increased risk of MI ( $\mathrm{Ji}$ et al. 2020). One

(b)

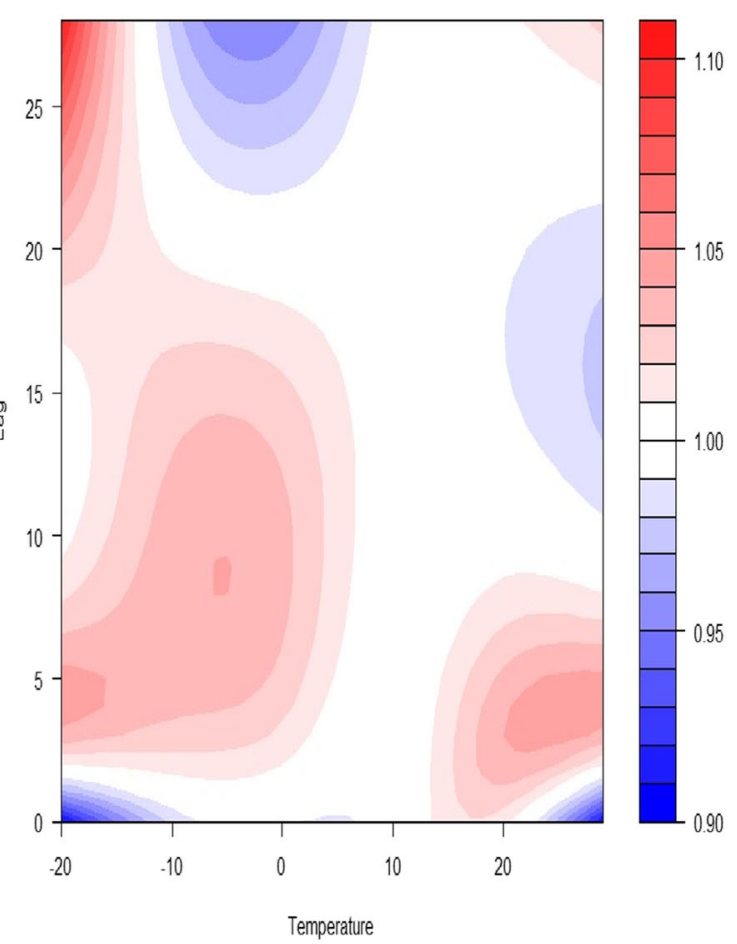

Fig. 10 Relationship between temperature and total admission in patients with AECOPD under different lag days (a three-dimension map, $\mathbf{b}$ contour map; AECOPD, acute exacerbation of chronic obstructive pulmonary disease) 


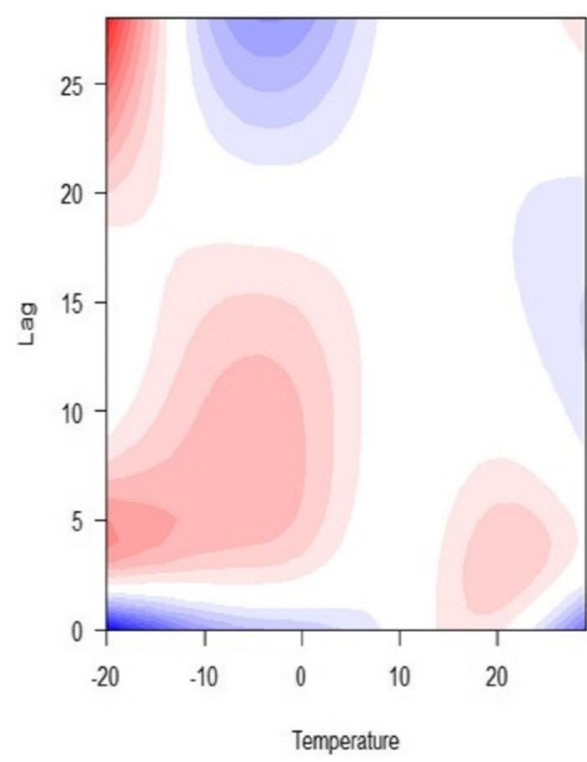

(a)

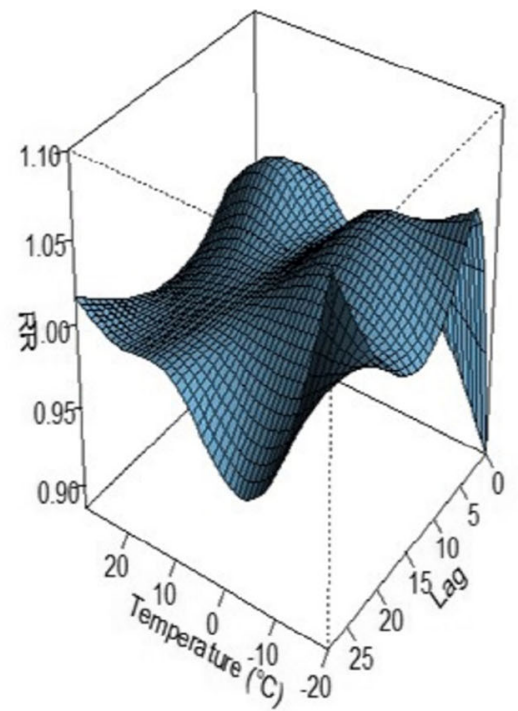

(c)
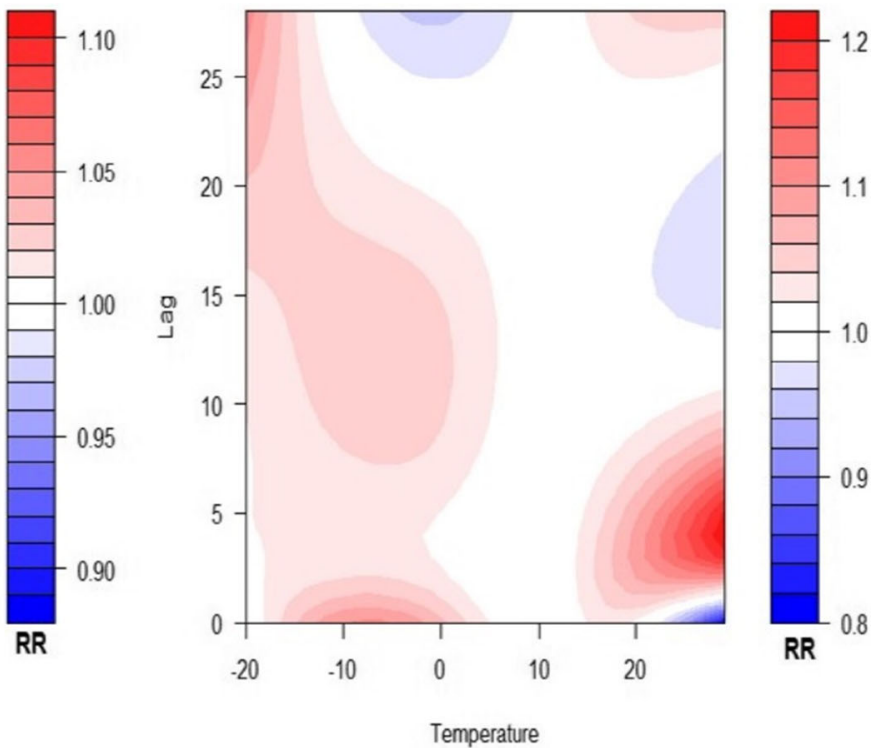

(b)

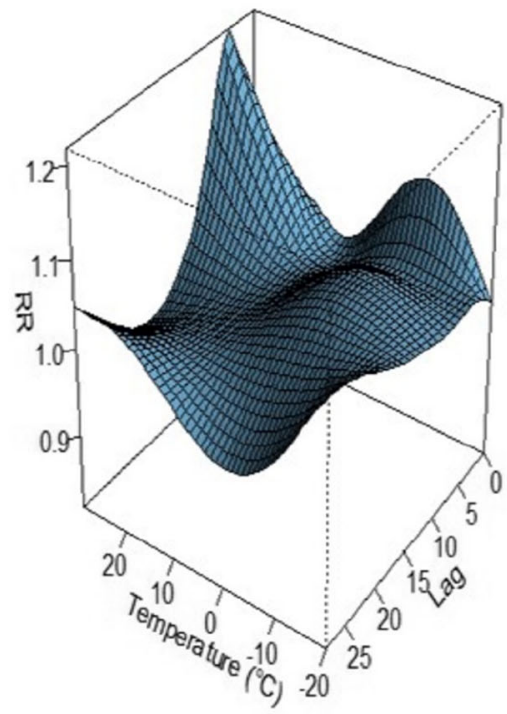

(d)

Fig. 11 The influence of ambient temperature on the risk of AECOPD admission based on the gender stratifications (a and $\mathbf{c}$, female; $\mathbf{b}$ and $\mathbf{d}$, male)

contradictory point is that the lowest risk of ambient temperature in our study was $10{ }^{\circ} \mathrm{C}$, while in a Brazilian study, it ranged between $22{ }^{\circ} \mathrm{C}$ and $28{ }^{\circ} \mathrm{C}$ (Ferreira et al. 2019). We speculate that latitude difference could account for this difference.

The results of this study provide evidence that ambient temperature affects hospitalization of AECOPD based on DLNM, which support previous studies. Zhao et al.'s research suggested that the OR of hospitalization was 1.05 (95\% CI 1.04-1.06) for each $5{ }^{\circ} \mathrm{C}$ increase in daily mean temperature at the national level (Zhao et al. 2019). Another study showed that with every degree Celsius decrease in mean weekly temperature, hospital admissions increased by $5.04 \%$. After accounting for adjustment factors, mean temperatures retained a statistical significance, with a mean increase of $4.7 \%$ in weekly admissions for each degree Celsius of temperature (Almagro et al. 2015). Extreme changes in temperature of cold and hot affect one's health. When external conditions change severely, the threshold value exceeds the body's ability to adapt, which can cause a variety of complex emergency responses in the body of the relevant population, and will have adverse effects on the physical and mental health of the population, as well as increase the occurrence or deterioration of corresponding weather-sensitive diseases such AECOPD. Thus, the respiratory system is more 


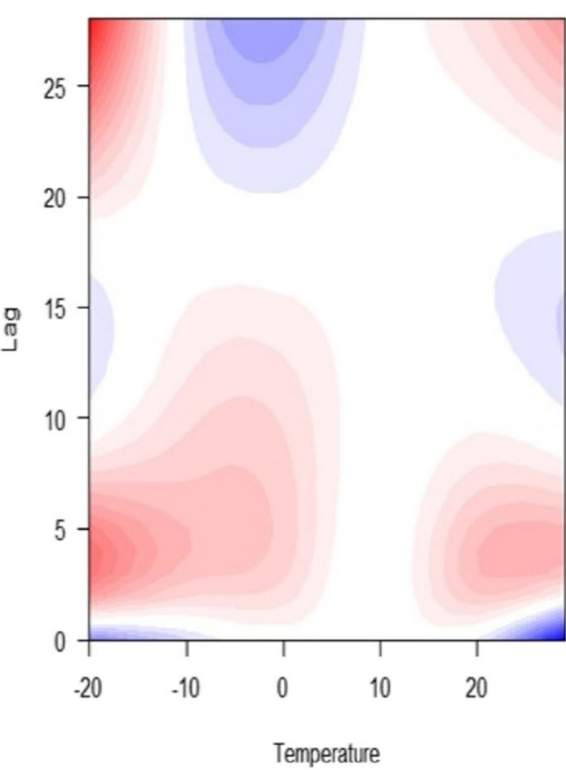

(a)

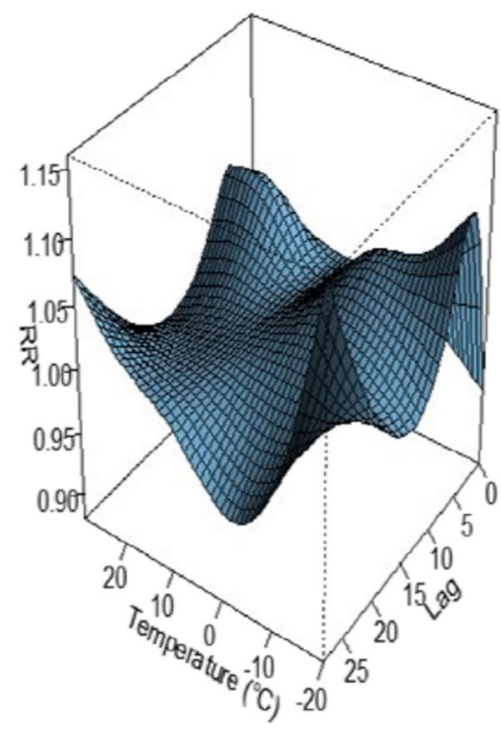

(c)
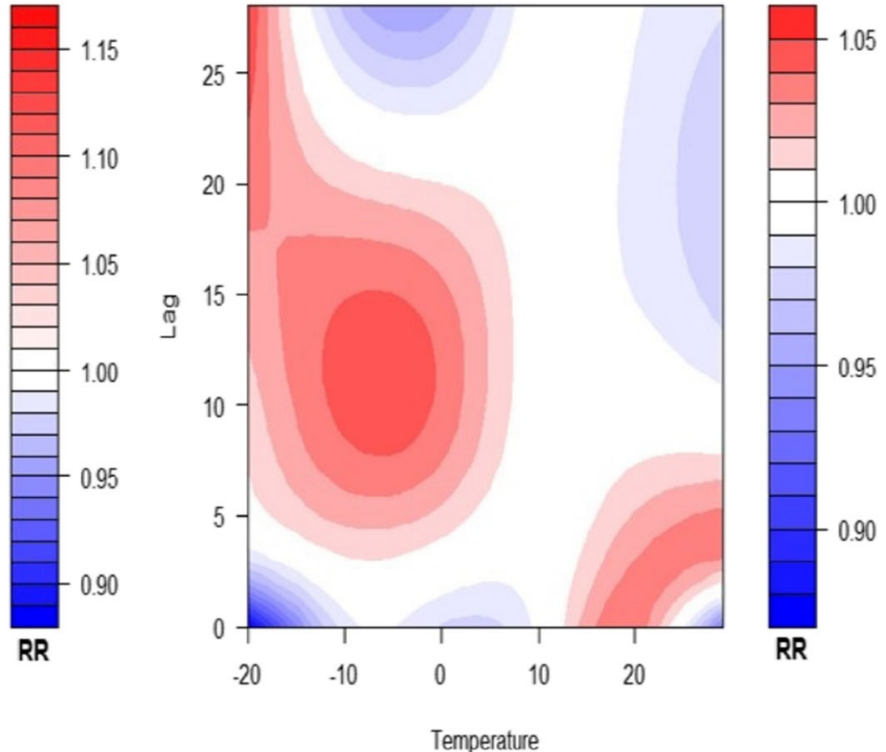

(b)

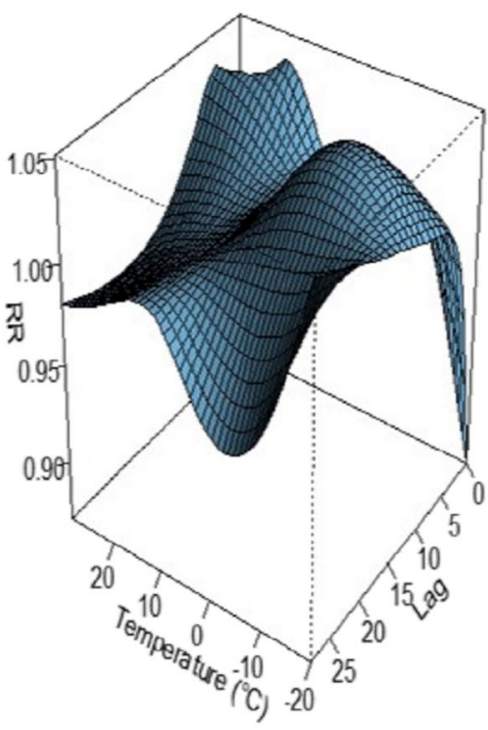

(d)

Fig. 12 The influence of ambient temperature on the risk of AECOPD admission based on the age stratifications (a and $\mathbf{c}$, age $\geq 65$ group; $\mathbf{b}$ and $\mathbf{d}$, age $<$ 65 group)

sensitive to outside temperature changes, especially for those $>65$ years old with COPD.

Supplementary Information The online version contains supplementary material available at https://doi.org/10.1007/s11356-020-11934-2.

Authors' contributions The contribution list is shown in the following form. Guarantor of integrity of entire study: Li Zhao. Study concepts: Cai Chen and Shijie Chang. Study design: Shijie Chang and Li Zhao. Literature research: Cai Chen and Yang Shen. Data acquisition: Xudong Zhang and Yang Shen. Data analysis/interpretation: Yang Shen and Xudong Zhang. Statistical analysis: Yang Shen and Wenxiu Qu. Manuscript preparation: Yang Shen, Cai Chen, and Xuejian Liu. Manuscript definition of intellectual content: Yang Shen, Cai Chen, and
Xudong Zhang. Manuscript editing: Xiyuan Li and Qianqian Lin. Manuscript revision/review: Cai Chen and Yang Shen.

Funding This work was supported by National Science Foundation of Liaoning (no. 64, 2018010534-301), Big Data Research for Health Science of China Medical University (Key Project no. 6), and the Project of Jinan "20 Universities” (\#2019GXRC040).

Data availability The data was obtained from the supplements.

\section{Compliance with ethical standards}

Conflict of interest The authors declare they have no conflict of interest. 
Ethical approval This study needs not ethical approval for that no patient participated in this study, and the personal information about patients were fully protected, because the information collected in this study contains admission date, gender, age, date of discharge, place of residence, admission number, and did not include patient's name and ID number.

Consent to publish All authors consent to publish this article in Environmental Science and Pollution Research.

\section{References}

Almagro P, Hernandez C, Martinez-Cambor P, Tresserras R, Escarrabill J (2015) Seasonality, ambient temperatures and hospitalizations for acute exacerbation of COPD: a population-based study in a metropolitan area. Int J Chronic Obstruct Pulmon Dis 10:899

Auler AC, Cássaro FAM, da Silva VO, Pires LF (2020) Evidence that high temperatures and intermediate relative humidity might favor the spread of COVID-19 in tropical climate: a case study for the most affected Brazilian cities. Sci Total Environ 729:139090

Bardach AE, Caporale JE, Rubinstein AL, Danaei G (2017) Impact of level and patterns of alcohol drinking on coronary heart disease and stroke burden in Argentina. PLoS One 12(3): 0173704

Béjot Y, Bailly H, Durier J, Giroud M (2016) Epidemiology of stroke in Europe and trends for the 21st century. Presse Med 45(12):e391e398

Chang CL, Shipley M, Marmot M, Poulter N (2004) Lower ambient temperature was associated with an increased risk of hospitalization for stroke and acute myocardial infarction in young women. J Clin Epidemiol 57(7):749-757

Chen C, Liu X, Wang X, Li W, Qu W, Dong L, Li X, Rui Z, Yang X (2019) Risk of temperature, humidity and concentrations of air pollutants on the hospitalization of AECOPD. PLoS One 14(11): e0225307

Chen C, Liu X, Wang X, Qu W, Li W, Dong L (2020) Effect of air pollution on hospitalization for acute exacerbation of chronic obstructive pulmonary disease, stroke, and myocardial infarction. Environ Sci Pollut Res 27(3):3384-3400

Dang TAT, Wraith D, Bambrick H, Dung N, Truc TT, Tong S, ..., Dunne MP (2019) Short-term effects of temperature on hospital admissions for acute myocardial infarction: a comparison between two neighboring climate zones in Vietnam. Environ Res 175:167-177

Duncker DJ, Klassen CL, Ishibashi Y, Herrlinger SH, Pavek TJ, Bache RJ (1996) Effect of temperature on myocardial infarction in swine. Am J Phys Heart Circ Phys 270(4):H1 189-H1199

Feng L, Li L, Liu W, Yang J, Wang Q, Shi L, Luo M (2019) Prevalence of depression in myocardial infarction: a PRISMA-compliant metaanalysis. Medicine 98(8):e14596

Ferreira LDCM, Nogueira MC, de Britto Pereira RV, de Farias WCM, de Souza Rodrigues MM, Teixeira MTB, Carvalho MS (2019) Ambient temperature and mortality due to acute myocardial infarction in Brazil: an ecological study of time-series analyses. Sci Rep 9(1):1-10

Forbes C (2010) MENH. Exponential Distribution. Springer, New York

Ganeshan K, Chawla A (2017) Warming the mouse to model human diseases. Nat Rev Endocrinol 13(8):458-465

Gasparrini A, Armstrong B, Kenward MG (2010) Distributed lag nonlinear models. Stat Med 29(21):2224-2234

GBD 2015 Chronic Respiratory Disease Collaborators (2017) Global, regional, and national deaths, prevalence, disability-adjusted life years, and years lived with disability for chronic obstructive pulmonary disease and asthma, 1990-2015: a systematic analysis for the Global Burden of Disease Study 2015. Lancet Respir Med 5(9):691
Giles LV, Tebbutt SJ, Carlsten C, Koehle MS (2018) The effect of low and high-intensity cycling in diesel exhaust on flow-mediated dilation, circulating NOx, endothelin-1 and blood pressure. PLoS One 13(2):e0192419

Gomes J, Damasceno A, Carrilho C, Lobo V, Lopes H, Madede T, Pravinrai P, Silva-Matos C, Diogo D, Azevedo A, Lunet N (2015) Triggering of stroke by ambient temperature variation: a casecrossover study in Maputo, Mozambique. Clin Neurol Neurosurg 129:72-77

Gosmanova EO, Mikkelsen MK, Molnar MZ, Lu JL, Yessayan LT, Kalantar-Zadeh K, Kovesdy CP (2016) Association of systolic blood pressure variability with mortality, coronary heart disease, stroke, and renal disease. J Am Coll Cardiol 68(13):1375-1386

Ji L, Wu D, Xie H, Yao B, Chen Y, Irwin DM, Huang D, Xu J, Tang NLS, Zhang Y (2020) Ambient temperature is a strong selective factor influencing human development and immunity. Genomics, Proteomics \& Bioinformatics. https://doi.org/10.1016/j.gpb.2019. 11.009

Kes VB, Jurasic MJ, Zavoreo I, Lisak M, Jelec V, Matovina LZ (2016) Age and gender differences in acute stroke hospital patients. Acta Clin Croat 55(1):69-78

Larsson SC, Wallin A, Wolk A, Markus HS (2016) Differing association of alcohol consumption with different stroke types: a systematic review and meta-analysis. BMC Med 14(1):178

Lawes CM, Bennett DA, Feigin VL, Rodgers A (2004) Blood pressure and stroke: an overview of published reviews. Stroke 35(3):776-785

Lian H, Ruan Y, Liang R, Liu X, Fan Z (2015) Short-term effect of ambient temperature and the risk of stroke: a systematic review and meta-analysis. Int J Environ Res Public Health 12(8):90689088

Lin YK, Maharani AT, Chang FT, Wang YC (2019) Mortality and morbidity associated with ambient temperatures in Taiwan. Sci Total Environ 651:210-217

Luo Y, Li H, Huang F, Van Halm-Lutterodt N, Xu Q, Wang A et al (2018a) The cold effect of ambient temperature on ischemic and hemorrhagic stroke hospital admissions: a large database study in Beijing, China between years 2013 and 2014 -Utilizing a distributed lag non-linear analysis. Environ Pollut 232:90-96

Luo L, Zhang Y, Jiang J, Luan H, Yu C, Nan P, Luo B, You M (2018b) Short-term effects of ambient air pollution on hospitalization for respiratory disease in Taiyuan, China: A time-series analysis. Int J Environ Res Public Health 15(10):2160

Ma Y, Jiao H, Zhang Y, Cheng B, Feng F, Yu Z, Ma B (2020) Impact of temperature changes between neighboring days on COPD in a city in Northeast China. Environ Sci Pollut Res 27(5):4849-4857

Mackay DF, Clemens TL, Hastie CE, Cherrie MP, Dibben C, Pell JP (2019) UVA and seasonal patterning of 56370 myocardial infarctions across Scotland, 2000-2011. J Am Heart Assoc 8(23):e012551

Mena LJ, Felix VG, Melgarejo JD, Maestre GE (2017) 24-Hour blood pressure variability assessed by average real variability: a systematic review and meta-analysis. J Am Heart Assoc 6(10):e006895

Pranata R, Huang I, Lim MA, Wahjoepramono EJ, July J (2020) Impact of cerebrovascular and cardiovascular diseases on mortality and severity of COVID-19-systematic review, meta-analysis, and metaregression. J Stroke Cerebrovasc Dis 29:104949

Qi X, Wang Z, Xia X, Xue J, Gu Y, Han S, Wang L, Li X, Leng SX (2020) Potential impacts of meteorological variables on acute ischemic stroke onset. Risk Manag Healthcare Pol 13:615-621

Ryan JM, Peterson MD, Ryan N, Smith KJ, O'connell NE, Liverani S, Anokye N, Victor C, Allen E (2019) Mortality due to cardiovascular disease, respiratory disease, and cancer in adults with cerebral palsy. Dev Med Child Neurol 61(8):924-928

Sajadi MM, Habibzadeh P, Vintzileos A, Shokouhi S, Miralles-Wilhelm F, Amoroso A (2020) Temperature, humidity, and latitude analysis to estimate potential spread and seasonality of coronavirus disease 2019 (COVID-19). JAMA Netw Open 3(6):e2011834-e2011834 
Sehra ST, Salciccioli JD, Wiebe DJ, Fundin S, Baker JF (2020) Maximum daily temperature, precipitation, ultra-violet light and rates of transmission of SARS-Cov-2 in the United States. Clin Infect Dis 71:2482-2487

Shah AS, Lee KK, McAllister DA, Hunter A, Nair H, Whiteley W, ... Mills NL (2015) Short term exposure to air pollution and stroke: systematic review and meta-analysis. Bmj 350:h1295

Song J, Lu J, Wang E, Lu M, An Z, Liu Y, ... Yao S (2019) Short-term effects of ambient temperature on the risk of premature rupture of membranes in Xinxiang, China: a time-series analysis. Sci Total Environ 689:1329-1335

Sun Z, Chen C, Xu D, Li T (2018) Effects of ambient temperature on myocardial infarction: a systematic review and meta-analysis. Environ Pollut 241:1106-1114

Thu Dang TA, Wraith D, Bambrick H, Dung N, Truc TT, Tong S, Naish S, Dunne MP (2019) Short - term effects of temperature on hospital admissions for acute myocardial infarction: a comparison between two neighboring climate zones in Vietnam. Environ Res 175:167177. https://doi.org/10.1016/j.envres.2019.04.023

Vodonos A, Novack V, Horev A, Salameh IA, Lotan Y, Ifergane G (2017) Do gender and season modify the triggering effect of ambient temperature on ischemic stroke? Womens Health Issues 27(2):245251

Wang X, Cao Y, Hong D, Zheng D, Richtering S, Sandset EC et al (2016) Ambient temperature and stroke occurrence: a systematic review and meta-analysis. Int J Environ Res Public Health 13(7):698

Wasserman EB, Zareba W, Utell MJ, Oakes D, Hopke PK, Frampton M, Chalupa D, Beckett W, Rich DQ (2014) Acute changes in ambient temperature are associated with adverse changes in cardiac rhythm. Air Qual Atmos Health 7(3):357-367

Zhao Q, Li S, Coelho MDSZS, Saldiva PHN, Xu R, Huxley RR, Abramson MJ, Guo Y (2019) Ambient heat and hospitalisation for COPD in Brazil: a nationwide case-crossover study. Thorax 74(11): 1031-1036

Zhu Z, Zhu S, Zhu J, Van Der Giet M, Tepel M (2002) Endothelial dysfunction in cold-induced hypertensive rats. Am J Hypertens 15(2):176-180

Publisher's note Springer Nature remains neutral with regard to jurisdictional claims in published maps and institutional affiliations. 